\title{
EL REGRESO DEL FUTURO Y LAS CUESTIONES DEL CONOCIMIENTO*
}

$\mathrm{L}$ as notas que siguen abren algunas cuestiones acerca de las implicaciones del regreso del futuro sobre la producción del conocimiento. Quizá muchos, si no todos, concuerden con que al final de los años ochenta todo lo que era opuesto al capitalismo, resistía al imperialismo o rivalizaba con él, había sido derrotado en todo el mundo. La especificidad de esa derrota consiste, en mi opinión, en la extinción de todo un determinado horizonte de futuro. Permítanme explicarme.

Durante los últimos quinientos años, es decir desde América, siempre ha habido al frente de todos, de todo el mundo, un horizonte brillante, incluso resplandeciente para ciertas promesas y en ciertos momentos: la modernidad, la racionalidad, el progreso, el liberalismo, el nacionalismo, el socialismo. El tiempo que ese horizonte anunciaba o prometía no

* Este texto fue publicado en Hueso húmero (Lima) $\mathrm{N}^{\circ} 38$, abril de 2001 . era pues la mera continuación del presente y del pasado. Era nuevo, entrañaba el cambio y anunciaba o prometía lo deseado o lo esperado, quizás incluso lo soñado. De todos modos, un sentido distinto para cada historia, en cada espacio / tiempo.

Debido a eso, las numerosas derrotas de las innúmeras luchas y de las muchas gentes que perseguían la conquista de algunas de esas metas fueron asumidas como transitorias siempre, como coyunturales muchas veces, esto es de plazo histórico, pero en caso alguno como finales o definitivas: el horizonte estaba allí delante, el buscado futuro estaba allá, invicto, con más alto resplandor cuanto más distante después de una derrota. Además, en los últimos tres siglos habíamos logrado, de veras, muchas victorias. Las formas peores de explotación habían sido arrinconadas. En muchas partes del mundo, la fauna, dominante había tenido que admitir, por lo menos, negociar los límites de la dominación y de la explotación. 
Los grandes imperios coloniales habían sido, casi todos, destruidos. Y en un momento hasta pareció real que la dominación y la explotación comenzaban, en ciertas áreas del mundo, a quedar atrás. Esas victorias sólo confirmaban la poderosa certidumbre de que las luchas se orientaban hacia un real horizonte de futuro, no a una visión engañosa. Para esa esperanza, toda derrota era sólo un momento de la lucha. Por eso, millones de gentes pudieron resistirlo todo, desde el exilio, la cárcel, la tortura, la muerte, hasta lo más personal y doloroso, el sacrificio o la pérdida de vidas amadas.

Estoy seguro de que muchos lo saben personalmente, país por país. O pueden haberse preguntado lo que sintieron los derrotados de la guerra civil española, toda una generación de revolucionarios de todo el mundo, temiendo o sabiendo que sería largo el tiempo de la derrota. Pero no hay testimonio alguno de esos años que indicara una renuncia al camino que el horizonte señalaba. «Si España cae, digo, es un decir, niños del mundo id a buscarla», clamaba Vallejo. Pero estaba seguro de que los niños del mundo irían a buscarla. En América Latina, la más análoga experiencia colectiva fue, probablemente, la caída de Allende en 1973, preludiada por la derrota de la Asamblea Popular en Bolivia, en 1972.
No es mi propósito, esta vez, hurgar en las determinaciones de esas derrotas. Lo que me interesa es señalar, primero, que desde fines de los sesenta (Shanghái 1967, París 1968, Praga 1969) comenzó a eclipsarse -y no ya sólo para una reducida y arrinconada minoría- el más brillante horizonte de futuro de ese período y que desde mediados de los setenta (el estallido de la crisis mundial del capitalismo) hasta fines de los ochenta (la "caída del muro" y la desintegración final del "campo socialista"), terminó extinguiéndose en todo el mundo. Y segundo, preguntar por sus implicaciones sobre las cuestiones del conocimiento.

Sobre lo primero, no creo que sean muchos los que nieguen que todos los movimientos, organizaciones y regímenes políticos que buscaban sea una importante desconcentración del control del poder, sea su radical redistribución para fines de los ochenta habían sido todos, en todo el mundo, derrotados. Todos ellos se extinguieron. Y con ellos se extinguió también, no sólo se eclipsó, todo horizonte de futuro para toda la década de los noventa, a menos que alguien estuviera dispuesto a sostener, en serio, que ese horizonte fuera el neoliberalismo. Para algunas de las vertientes neoliberales, inclusive había llegado al fin de la historia (Fukuyama). Por primera vez en quinientos años los 
más ilustres sueños de la especie parecían haber sido enterrados. Extraviada la esperanza, el temor oscurecía de nuevo el horizonte ${ }^{1}$.

Sobre lo segundo, sugiero que la extinción del horizonte de futuro se hizo perceptible para todos sobre todo desde fines de los ochenta. En todo caso, es desde entonces que la intersubjetividad mundial aparece marcada, intempestivamente, por dos rasgos: uno, para muchos la extraña sensación de que las ideas, las propuestas, las promesas y las razones de cambios históricos radicales pertenecían a un pasado súbitamente remoto; dos, el abandono, rápido y masivo e igual de repentino, de las perspectivas mentales, de las cuestiones y categorías conceptuales asociadas a aquellas que preguntaban por el poder en la existencia social y por los modos de su crisis y de su cambio radical o de su remoción definitiva. $\mathrm{O}$, para decirlo en fácil, lo que se reconocía como el "pensamiento crítico" era abandonado sin debate. El único

1 Todos recuerdan sin duda el Prometo de Esquilo. No tengo a la mano ningún ejemplar mientras escribo estas notas. Cito, pues, de memoria su diálogo con las náyades que van a visitarlo encadenado:

- ¿Qué has hecho para merecer este castigo?

- He desterrado de los hombres el temor a la muerte.

- ¿Y cómo has hecho para lograr ese milagro?

- He hecho nacer entre ellos la ciega Esperanza. debate, si de verdad lo fue, en América Latina tiene en rigor virtud testimonial: la "crisis de paradigmas". Y fue nada menos que Fernando Henrique Cardoso, uno de los primeros, si no el primero, en acuñar la fórmula.

Son muchos y muy fuertes los núcleos de cuestiones que aquí se abren. En esta ocasión, quiero apuntar sólo a dos de ellos. En primer lugar, a las relaciones entre las perspectivas históricas del imaginario y las del conocimiento. Y en segundo lugar, a algo más complejo: las relaciones entre el imaginario, las acciones sociales y los modos de producción de conocimiento.

\section{IMAGINARIO Y CONOCIMIENTO}

La idea de un horizonte de futuro en cuanto un tiempo nuevo para la existencia social y de ese modo portador de un sentido nuevo de historia, total o parcial, radical o de superficie, apunta obviamente a una específica perspectiva de imaginario: la de un imaginario histórico. Muy diferente, en consecuencia, que la de un imaginario místico o mágico que trasciende a la historia.

La perspectiva de imaginario histórico, que ha sido mundialmente hegemónica has- 
ta hace poco, comenzó con América, aunque su elaboración central correspondiera a Europa. Implicó un cambio de porte histórico para las relaciones intersubjetivas de la población de todo el mundo. Y para Europa, en particular, el abandono del pasado como la edad dorada de la humanidad, por la del futuro como el continente histórico de la esperanza. Dos elementos me interesa destacar en esa específica perspectiva de imaginario: 1) la idea de modernidad / racionalidad asociada a las ideas de progreso y de mercado; 2) la idea de democracia como un interés social concreto, como la expresión cimera de le modernidad ${ }^{2}$.

2 En el poder del capital el mercado es el piso de la igualdad, pero es también su techo, es decir su límite. Por lo tanto, dentro de ese patrón de poder la igualdad no puede dejar de ejercerse sino como un conflicto irresoluto que, de un lado, ha llevado a institucionalizar la negociación de los límites, las condiciones y las modalidades de la dominación / explotación / conflicto, lo que se expresa en la igualdad jurídico-política de desiguales sociales y en el universo institucional del moderno Estado-nación. Pero de otro lado, lleva a un continuado conflicto de una parte por la reducción continua de tales límites; de otra parte, por la continuada ampliación y profundización de la igualdad en la sociedad misma, lo que, por supuesto sobrepasa los límites del poder del capital y del moderno Estado-nación. Esa relación es
Esta vez no iré muy lejos en esta indagación. Lo que me interesa es hacer notar que sin esas ideas / imágenes, determinadas preguntas a la "realidad", es decir a la experiencia social, al poder en primer término, la elaboración de las cuestiones respectivas, la búsqueda de las instancias de la "realidad" en donde encontrar los elementos de respuesta, los campos de relaciones que se establecen o se descubren en esa búsqueda, las explicaciones y los sentidos que se elaboran para esas respuestas, no serían posibles. O lo serían de modo muy diferente del que ha llevado a la constitución del conocimiento "crítico", la perspectiva de conocimiento que hizo del poder del capital la cuestión central de investigación, de debate y de teoría científica. En otros términos, sugiero que la perspectiva de conocimiento implicada en el "pensamiento crítico" y en la "teoría crítica de la sociedad", fue compañera y asociada de una perspectiva de imaginario también "crítico" que se instaló junto con la modernidad.

contradictoria y conflictiva, pero no es evitable. Es una necesidad histórica. En ese específico y preciso sentido constituye un interés social concreto, el que define la modernidad. 


\section{IMAGINARIO E HISTORIA}

¿Qué hizo que tales perspectivas de imaginario y de conocimiento que se desarrollaron asociadas se derrumbaran y se extinguieran también asociadas? Si las cuestiones que la segunda indagaba estaban asociadas a la primera, ¿podría decirse que fue la extinción de ese específico horizonte de futuro lo que arrastró a la perspectiva de conocimiento que le estaba asociada? ¿O fue al revés, la derrota de las acciones sociales vinculadas a esa perspectiva de conocimiento lo que llevó a la extinción de la perspectiva de imaginario con la cual estaba asociada?

La extinción de todo un horizonte de futuro o perspectiva de imaginario histórico no podría ser explicada sino por cambios muy profundos en las fuentes intersubjetivas de donde surtía. Pero eso, sin duda, vale lo mismo para lo que ocurre o puede ocurrir con una dada perspectiva de conocimiento histórico social. En otras palabras, lo que estoy sugiriendo es que el patrón capitalista de poder ha venido modificando las fuentes mismas que alimentaban las corrientes del específico imaginario histórico, que podríamos llamar "crítico" y del conocimiento social "critico" que le estaba asociado. En ambos lados se trata sin duda alguna de una profunda victoria del capitalismo.
¿Se desprende de allí, simplemente, que el capitalismo ha salido victorioso, porque es invencible? ¿Y que, como lo propone el pensamiento "posmodernista", esa crítica, sus propuestas y sus proyectos eran solamente "grandes narrativas", quiméricas en lo fundamental, que hay que admitir que el poder o es una abstracción teóricamente impertinente o un dato inmutable de la vida tal como es, y respecto del cual, en consecuencia, apenas tiene sentido ubicar sus intersticios más aptos donde jugar con la libertad individual, como lo propone hoy la lectura postmodernista de Foucault?

En la sociedad, todo poder es una relación social de dominación / explotación / conflicto. Esos tres elementos constitutivos de toda relación de poder están allí en medidas y formas diferentes cada cual, según las situaciones, los espacios / tiempos concretos. El poder que se articula en torno del capitalismo ha resultado ser hasta ahora más fuerte que sus adversarios. Eso no es necesariamente, sin embargo, una demostración de su invencibilidad, sino la indicación de una relación de fuerzas que lleva a indagar por la de sus adversarios: ¿dónde reside su debilidad?

Para comenzar esa exploración, sugiero partir de otra pregunta, indispensable: ¿podría un imaginario histórico, y "crítico" en particular, 
vivir y desarrollarse largamente sin referentes demostrativos, en consecuencia victoriosos, en la experiencia concreta? Probablemente, no. O mejor, sin duda no. Porque un imaginario histórico no es lo mismo que un imaginario místico o mágico sobre un universo que trasciende a la historia concreta. Respecto de estos últimos, la experiencia concreta o no es un referente demostrativo necesario, porque ese imaginario la trasciende, o es siempre, de todos modos, una continua demostración del imaginario. Por ejemplo, para quien cree que el universo ha sido "creado", la experiencia es una continua demostración. Pero para quien cree en la “inmaculada concepción”, la experiencia es del todo irrelevante. Sin embargo, ambas creencias corresponden a una misma perspectiva de imaginario místico.

Desde ese punto de vista, no es arbitrario, ni impertinente, sugerir que entre el imaginario histórico-crítico y la experiencia histórica concreta, las relaciones originalmente ceñidas, casi podría decirse que simétricas si se consideran los siglos XVIII y XIX desde la perspectiva europea, durante el siglo XX han tendido hacia un creciente desencuentro, el que ha ido llevando a la frustración continua y a la subalternización final de la subjetividad vinculada a ese imaginario. Es decir que una parte de la experiencia concreta, precisamente aquella vinculada a la fuerza hegemónica, responsable en consecuencia por las derrotas o las victorias, ha tendido a orientarse y a desarrollarse en una dirección distinta a la del imaginario crítico. $\mathrm{Y}$ en ese caso, las acciones destinadas a la materialización del imaginario eran o derrotadas o, mucho peor, precisamente las victorias mismas conducían a otra parte . $^{3}$.

Quizás es útil una corta historia. Desde comienzos del siglo XX y en especial desde la derrota de la República en España, se reduce el espacio del debate y de los movimientos sociales para los cuales la lucha por el control del Estado-nación no es el camino que lleva al horizonte de futuro donde la dominación y la explotación no son las que organizan la sociedad. Su espacio se reduce de tal modo que para una inmensa mayoría de la población mundial esas corrientes simplemente no existen. Se instala, en cambio, como mundialmente hegemónico

3 Fue quizás en el cine italiano, sin duda no por mera coincidencia, donde por primera vez y desde tan temprano como desde los sesenta, comienzan a ser elaboradas las imágenes de ese desencuentro. Recuerdo sobre todo la devastada conciencia, atrapada entre el cinismo y la angustia, de "Nos habíamos amado tanto". 
el llamado "materialismo histórico" y desde la llamada Revolución socialista en Rusia, en 1917, la vertiente que conserva su nombre político original corno socialdemocracia cede su lugar en la hegemonía mundial a la que adopta el nombre de "marxismo-leninismo" y que pasa a ejercer el dominio mundial desde el nuevo Estado ruso, a partir de 1924.

Se sabe bien que ya desde 1917 algunas importantes minorías habían introducido críticas radicales sobre el carácter y el futuro del nuevo poder instalado en Rusia y que se reclamaba como revolucionario y socialista. Así, entre 1917-1918 Rosa Luxemburg denuncia el despotismo, Anton Pannekoek la contrarrevolución burocrática, Rodolfo Mondolfo el capitalismo de Estado que usurpa el lugar del socialismo y desde 1927 sobre todo Trotsky y sus seguidores denuncian las "deformaciones burocráticas" en lo que, sin embargo, reconocen aún como "Estado obrero"4. Pero a pesar de las críticas,

4 Es interesante e intrigante que al final de su libro principal en ese debate, La revolución traicionada, Trotsky pareciera sospechar que quizás había algo más que una "deformación burocrática" en el proceso de Rusia. De otro modo no podría explicarse que sugiriera que si esa situación fuera a durar mucho tiempo, digamos unos cincuenta años, habría que pensar en que se trataba de otro sistema de dominación y de explo- a pesar de la experiencia de los "procesos" de Moscú, del asesinato de Trotsky, de los campos de trabajo forzado, Rusia y los bolcheviques lograron establecer una auténtica constelación de prestigio sobre los revolucionarios de todo el mundo. En particular, su apoyo a las luchas anticoloniales y antiimperialistas de todo el mundo hizo de Rusia un polo mundial de atracción y de dirección política, y su prestigio y su influencia no hicieron sino agrandarse después de la Segunda Guerra Mundial con la formación del "campo socialista" que incluía a todos los países de Europa Oriental, a China después de la Revolución China (1949) y a Cuba, después de 1962.

tación. Pero no hay cómo inferir la propuesta teórica alternativa, ni la perspectiva de conocimiento a la cual dicha sospecha pudiera estar asociada. Sus seguidores, los llamados trotskistas, nunca recogieron esa propuesta, bien pasados esos cincuenta años, ni siquiera cuando se publicó el notable libro de Rudolf Bahro, Die Alternative (Koln: Europaische Verlagsansalt, 1977; Barcelona: Editorial Malenales 1979) cuya tesis central es, precisamente, que el poder en Rusia y en el "campo socialista" no sólo no es socialista, sino que se trata de un patrón históricamente nuevo de dominación y de explotación. Véase también de Bahro: El socialismo realmente existente. Seis conferencias críticas (Lima: Mosca Azul editores, Serie Debate Socialista $\mathrm{N}^{\circ} 3$, 1981) con "Prólogo" de Aníbal Quijano y Mirko Lauer. 
Sin embargo, no mucho después de la Segunda Guerra Mundial, en el "campo socialista" comenzó una secuencia de hechos que comenzaron a reintroducir dudas sobre el carácter real de dicho "campo" respecto del horizonte de futuro, del "imaginario crítico" anticapitalista. Desde entonces, las dudas no hicieron sino crecer y hacerse más profundas. Primero fue la ruptura de Tito y de Yugoeslavia con Stalin y con la URSS y dentro de la propia Yugoeslavia la disidencia que denuncia a la burocracia dominante como una "nueva clase" (Djilas). Luego fue la revuelta obrera de Berlín Este, en 1953, tan brutalmente reprimida que Brecht no dudó en hacer pública su feroz ironía: ya que el Estado estaba tan descontento de sus ciudadanos, debería elegir otros. No mucho después, en 1956, fue la Revolución en Hungría, en donde fueron los propios tanques soviéticos los encargados de la sangrienta represión. A esos hechos se añadieron pronto las repetidas revueltas de los obreros de Polonia, durante las décadas del cincuenta y del sesenta.

Tras cada uno de esos hechos, numerosos intelectuales ligados a los partidos comunistas en muchos lugares, especialmente en Europa, decidieron romper con el partido. Después de la revuelta húngara se estima en unos 6 mil los intelectuales europeos que abandonaron a esos partidos (pienso en el desolado balance de La Somme et la Reste de Henri Lefevre). La gran mayoría de ellos no dejó, sin embargo, de ser socialista y marxista. Las dudas se hicieron definitivas cuando a la muerte de Stalin comenzaron a ser confirmadas, desde dentro mismo de la fauna dominante, las acusaciones de despotismo, de criminalidad y de abusos del régimen estaliniano. El célebre Informe Kruschev, ante el XX Congreso del PCUS, tuvo un efecto devastador, a pesar de que los partidos estalinianos procuraban embutir todo en la inefable fórmula de "culto a la personalidad". Después vino la ruptura chino-rusa, la expansión de la influencia maoísta como la versión substituta del estalinismo. Pero la masacre de la Comuna de Shanghái, en 1967, ordenada por el propio Mao, anunciaba ya la orientación y el desemboque futuros del régimen chino. La secuencia final que lleva desde la represión y ocupación de Praga, 1969, por los mismos tanques rusos, liquidando lo que prometía ser una liberalización democrática del despotismo burocrático, pasando por la revuelta finalmente exitosa de los obreros de Solidarnosc en Polonia, 1976, a pesar del golpe militar estaliniano del general Jaruzselsky, hasta la "caída del muro" en Berlín en 1989 y la desintegración del "campo socialista”, está 
sin duda fresca aún en la memoria de todos y no requiere más comentarios.

Esa secuencia fue en verdad suficientemente larga para mostrar al mundo la naturaleza real del patrón de poder impuesto en Rusia y en todo el "campo socialista" desde octubre de 1917. Su minoría dirigente -como es evidente por lo que ha hecho en todas partes después de la "caída"- durante ese período estaba interesada cada vez más en la privatización del control del poder, no en su destrucción 5 . Y debido a eso las disidencias, como fueron lla-

5 "Los peligros de la democracia" es, precisamente, el título del artículo de Gavril Popov, alcalde de Moscú, el primero electo de la historia de Rusia, después de la desintegración de la URSS. La ominosa tesis de Popov -profesor de Marxismo y Dialéctica hasta apenas la víspera de tal desintegración- es que la destrucción del "socialismo real" en Rusia fue la obra de una alianza entre las masas trabajadoras y la inteligencia soviética, pero que ambos sectores persiguen intereses opuestos: las masas quieren la democracia para conquistar la igualdad social y el control del poder, mientras que esa inteligencia está interesada en una nueva jerarquización de la sociedad. Es decir, cuanto más amplia sea la democracia las masas avanzarían en dirección de la igualdad social, en contra de los intereses de la inteligencia. Por eso, para Popov, la democracia es un peligro que es necesario controlar ("Dangers of Democracy" en New York Review of Books, 16 de agosto de 1997, p. 27). madas las tendencias revolucionarias críticas dentro de los países del "campo socialista", se ampliaron rápidamente y se hicieron explícitos los conflictos entre los controladores del poder y sus víctimas.

Fuera de esos países, los millones de trabajadores y de revolucionarios socialistas en todo el mundo continuaron combatiendo por las promesas del brillante horizonte de futuro asociado a la idea de socialismo. Y la crítica revolucionaria del poder comenzó a enfrentarse tanto al capitalismo como al despotismo burocrático dentro del "campo socialista". Como Rudy Dutschke dijera en un mitin de Berlín poco antes de ser víctima de un intento de asesinato, era perceptible un poder despótico que comenzaba a extenderse desde Washington hasta Vladivostok y era urgente enfrentarlo antes de que se hiciera más fuerte.

Fue, pues, tanto al lado como separado de la hegemonía del "materialismo histórico" o "marxismo-leninismo", que desde los años sesenta se desarrolló en todo el mundo un nuevo movimiento social que se dirigía no solamente a la subversión del poder capitalista-imperialista, sino también a la del despotismo burocrático del "campo socialista". Ya no se trataba solamente de la liberación de los obreros del trabajo explotador, sino de la liberación de las 
gentes, de todas las gentes, de la dominación y de la discriminación en cada uno de los aspectos de la vida humana en sociedad: de la mujer, de los homosexuales, de los jóvenes, de los discriminados por razones racista-etnicistas. Se trataba ahora de la plena liberación de la subjetividad, de la producción del conocimiento de sus ataduras en el poder, de la liberación de cada uno de los campos de la cultura, del arte en especial, de la defensa de la naturaleza frente la depredación humana, capitalista en particular. Se trataba de la liberación de las gentes de la autoridad encarnada en la "razón de Estado".

La lucha por la ampliación y la profundización de la democracia en la sociedad, no sólo en el Estado-nación, no sólo como negociación de los límites y de las condiciones de la explotación y de la dominación, ni sólo como liberación del trabajo explotado, sino, ante todo, como la materialización de la idea de igualdad social de las gentes, como modo de las relaciones cotidianas entre las gentes, en cada ámbito de la existencia social, en todo el mundo, emergió como el núcleo más brillante del nuevo horizonte de futuro. Esas eran las propuestas y las imágenes de todos los movimientos de los jóvenes en ámbitos diversos, en Shanghái en 1967, en mayo del París de 1968, en Tlatelolco en ese mismo año, en las calles de Praga en 1969, en la parte más activa del movimiento juvenil en los Estados Unidos, incluso en el medio millón de gentes que concurrieron a la fiesta de la subversión de Woodstock.

Un horizonte de futuro aún más encendido comenzó a instalarse. En otros términos, un imaginario crítico más radical y más global, que se enfrentaba al capitalismo y al despotismo burocrático del "socialismo real", al mismo tiempo.

Después de casi un siglo retornaba el debate sobre el lugar del Estado en la articulación del poder, liberarse del cual era el sentido de toda revolución. Se trataba, en suma, de un imaginario asociado a la liberación de las gentes del poder, de todo poder. Y como es normal en la historia, fueron la música, las artes visuales, la poesía y el relato las formas de expresión más ceñidas del nuevo imaginario.

Nada sorprendente, desde ese punto de vista, que los dos poderes, el del capitalismo privado y el del despotismo burocrático, actuaran de algún modo al unísono para derrotar ese nuevo asalto al cielo. Tuvieron entonces pleno éxito. Pero el resultado fue esta genuina catástrofe histórica que estoy aquí tratando de hacer perceptible: la derrota de todos los movimientos, organizaciones, regímenes, opuestos a o 
rivales del capital y de la burocracia, en todo el mundo, hasta su virtual extinción. Y con ellos, la extinción también de todo horizonte de futuro, de todo imaginario crítico, el ensombrecimiento de un horizonte que pasaba a estar ocupado, total y únicamente, por las predatorias necesidades del capital financiero.

La derrota del movimiento revolucionario mundial fue también la derrota del nuevo "imaginario crítico". Este no tuvo la duración suficiente como para generar también su propio "pensamiento crítico" y su propia "teoría crítica" de la sociedad. Una década o década y media no son, sin duda, suficientes para pasar del nuevo imaginario a la producción de un nuevo modo de conocimiento. Es pertinente, en consecuencia, preguntarse también qué ocurrió con el llamado "pensamiento crítico" anterior y con su producto la llamada "teoría crítica de la sociedad". Primero, porque esa perspectiva de conocimiento era la que orientaba, conducía en la práctica, las acciones sociales hacia el horizonte de futuro. Y, segundo, porque era también ella misma el tribunal que juzgaba y evaluaba la orientación y la eficacia de las acciones.

Tampoco en este asunto quiero ir aquí más lejos. Me limitaré, por ahora, a reiterar lo que ya he tratado de mostrar en otros textos:
1. Que ese "pensamiento crítico" y esa "teoría crítica" de la sociedad se constituyeron dentro de la perspectiva eurocéntrica de conocimiento y referidas al poder social específico de Europa. Aunque ya con el atisbo de las principales dificultades epistemológicas de dicha perspectiva, las preguntas a la realidad y las categorías conceptuales básicas fueron elaboradas en y para la experiencia europea.

2. La hegemonía mundial fue ganada por la más definidamente eurocentrista de las versiones de tal "pensamiento crítico" y de su respectiva "teoría crítica": el "materialismo histórico" o "marxismo-leninismo". Y fue esa versión la que tenía el dominio en la conducción de las acciones y en la evaluación de la orientación y de la eficacia de éstas desde el comienzo del siglo XX.

3. Esa vertiente del pensamiento y de la teoría social ha sido desde entonces alimentada, en lo fundamental, por la perspectiva cognitiva del eurocentrismo y su desarrollo ha corrido, por eso, ceñido a las tendencias de tecnocratización creciente de esa específica racionalidad.

Ese específico proceso de la versión mundialmente dominante del pensamiento y de 
la teoría social que conducía y evaluaba las acciones frente al poder, fue generando un desencuentro creciente entre el imaginario crítico, la experiencia social concreta y la teoría social. Ese desencuentro se hizo cada vez más perceptible, esto es para cada vez mayor número de gente, desde el fin de la Segunda Guerra Mundial.

Las tendencias más profundas del capitalismo (no sólo del capital) que han llevado a la situación actual ya estaban en visible curso desde mediados de los sesenta: las limitaciones crecientes a la mercantilización de la fuerza individual de trabajo; la "desocupación estructural"; la sobre-acumulación en unas áreas y la sub-acumulación en otras; la fragmentación del trabajo; la tecnocratización del conocimiento; la reducción del espacio de la democracia. Pero todo eso estaba en conflicto con un importante proceso de desconcentración del control del poder, en la mayor parte de los casos, y de efectiva redistribución de ese control, en menos casos. Y finalmente, con una ola mundial de cuestionamientos de las bases mismas del poder del capitalismo, entre mediados de los sesenta hasta mediados de los setenta.

Por eso, cuando estalla la crisis mundial del capital a mediados de los setenta, para la inmensa mayoría de la "izquierda" del mundo debió parecer que las victorias anticapitalistas estaban más próximas. Si no fue así, en consecuencia, no se debió a que las gentes hubieran comenzado a salir de los horizontes críticos del imaginario, sino a que la conducción intelectual y política mundialmente hegemónica había hecho más profunda y definitiva su pertenencia y su identidad eurocéntrica. Sugiero, por eso, abrir esta nueva cuestión en el laberinto: la derrota mundial en la dimensión material estaba ya dada, primero, en la dimensión intelectualpolítica. La derrota entregó a las víctimas del capitalismo, en su mayoría, a un vacío del imaginario. A una minoría, a ingresar en los caminos conformistas del imaginario. Pero a los profesionales del conocimiento, a ellos, en su mayoría abrumadora, les llevó a fortalecerse en sus propensiones eurocéntricas y abandonar sin complicaciones psicológicas los elementos cognitivos de la perspectiva crítica de conocimiento.

\section{A LA HORA DE LA RESISTENCIA MUNDIAL: ¿EL REGRESO DEL FUTURO?}

Al terminar la década de los noventa, también el tiempo de la derrota está comenzando a terminar. La resistencia contra las más perversas 
tendencias del capitalismo, lo que se conoce con el nombre de globalización, está ya levantándose en todo el mundo. En América Latina, en particular en América del Sur, ningún país esta exceptuado de la creciente resistencia de los trabajadores y de la inestabilidad política que allí se genera.

Ese nuevo período de acciones sociales que enfrentan el poder capitalista mundial, comienza a desarrollarse en un escenario casi totalmente cambiado, en su estructura, en sus elementos específicos, tanto en la dimensión material, como en la intersubjetiva de las relaciones sociales. En especial, en un tiempo de reconcentración casi total del control del poder, del lado de los dominantes, y de fragmentación y desconcentración social, en el lado de los trabajadores.

No es inevitable que las versiones eurocéntricas convencionales (el "materialismo histórico") obtengan la primacía inmediata en el comando de la resistencia. Pero casi siempre ocurre que las gentes comienzan a actuar no sólo frente a sus problemas y a sus necesidades, sino también apelando a su memoria para definir las nuevas situaciones y orientarse en ellas.

En todo caso, la resistencia mundial ya comenzada implica, o puede implicar, la recons- titución de un imaginario crítico, la reconstitución de otro horizonte de futuro, diferente del que se ha extinguido. Aún no está con nitidez a la vista ese probable horizonte nuevo. Pero si la resistencia no es aplastada pronto y del todo, esa será una indicación de que hay, de todos modos, un horizonte de futuro en plena constitución. ¿Cuáles son, cuáles serán, las imágenes históricas que allí se instalen? Sobre ellas, por el momento, apenas puede tenerse sospechas de imágenes: la que fue derrotada y parecía enterrada, la esperanza más iluminada de los años sesenta, la democracia como igualdad social, no sólo como ciudadanía en el Estadonación, como legitimación de la diversidad de las gentes y de la heterogeneidad de sus creaciones, como liberación de la vida en sociedad respecto de cada una de las formas y de los mecanismos de explotación, de dominación, de discriminación, como descolonización y liberación del conocimiento y del imaginario, como la co-presencia de la igualdad, de la solidaridad y de la libertad de todas las gentes en todas las sociedades, tenderá a buscar y a producir otro universo institucional donde pueda, realmente, ser expresada y defendida. Las disputas y combinaciones entre el moderno Estado-nación y la nueva Comunidad, serán quizás las que expresen la búsqueda de 
nuevas formas institucionales de autoridad donde el poder no esté presente o esté reducido y controlado su espacio.

Lo que aquí interesa realmente es la exploración, por incipiente que pudiera ser, necesaria de todos modos, de un horizonte paralelo de conocimiento, de una racionalidad no-eurocéntrica, que pueda también ser parte del propio horizonte de futuro. En cualquier caso, hay una tarea planteada. 